\title{
Trends in biotech literature 2006
}

\author{
Gaspar Taroncher-Oldenburg and Andrew Marshall
}

Unsurprisingly, microRNAs dominate the list of highest cited papers, and the area is witnessing rapid growth. The number of papers in other fields, such as proteomics, nanotech and RNA interference, also

continues to expand; $80 \%$ of the publications specifically reporting

\section{Number of biotech journal articles by region}

Last year, Japan leap-frogged Germany and the UK, France fell behind Spain and Italy, China and India continued to grow and Switzerland entered the top 15 .

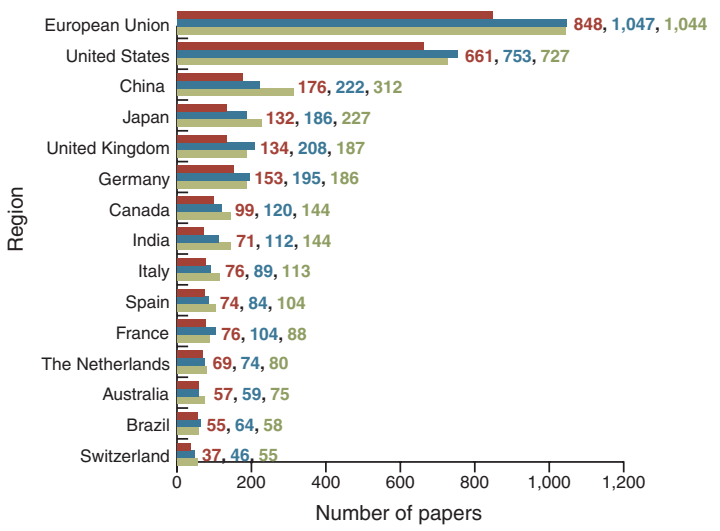

Based on search for papers containing "biotechnology" in abstract. Source: Nationa Center for Biotechnology Information's PubMed

\section{Historical trends in biotech fields}

Papers on proteomics and nanotech continued rapid growth in numbers; those on microRNA and cancer stem cells nearly doubled.

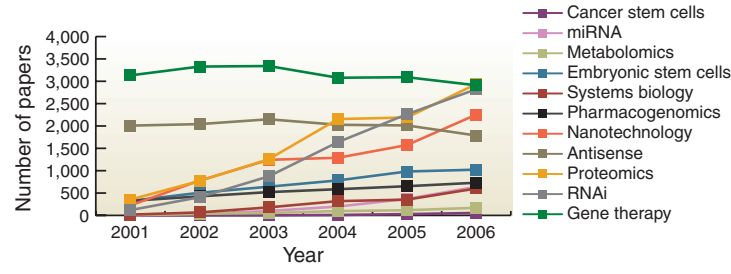

Obtained using fields (e.g., "proteomics") as search term in published papers. Source: National Center for Biotechnology Information's PubMed; BioPharm Reports

Biotech journal impact

\begin{tabular}{|c|c|c|c|}
\hline Primary research journal & $\begin{array}{l}\text { Impact } \\
\text { factor }\end{array}$ & Review journal & $\begin{array}{l}\text { Impact } \\
\text { factor }\end{array}$ \\
\hline Briefings in Bioinformatics & 24.4 & Annual Review of Pharmacology & 22.8 \\
\hline Nature Biotechnology & 22.7 & Nature Reviews Drug Discovery & 21.0 \\
\hline Nature Chemical Biology & 12.4 & Pharmacological Reviews & 16.9 \\
\hline Genome Research & 10.3 & \multirow{6}{*}{$\begin{array}{l}\text { Annual Review of Biomedical } \\
\text { Engineering }\end{array}$} & \multirow[t]{6}{*}{10.5} \\
\hline $\begin{array}{l}\text { Proceedings of the National } \\
\text { Academy of Sciences USA }\end{array}$ & 9.6 & & \\
\hline $\begin{array}{l}\text { Molecular and Cellular } \\
\text { Proteomics }\end{array}$ & 9.6 & & \\
\hline $\begin{array}{l}\text { Clinical Pharmacology \& } \\
\text { Therapeutics }\end{array}$ & 8.1 & & \\
\hline Stem Cells & 7.9 & & \\
\hline Molecular Systems Biology & 7.4 & & \\
\hline
\end{tabular}

Source: ISI categories Biotechnology \& Applied Microbiology; Engineering, Biomedical cancer stem cells were published in the past two years. China and India continue to increase their output of biotech papers; France fell behind Spain and Italy; Switzerland entered the top 15 for the first time.

\section{Most cited institutions in pharmacology and toxicology}

From 1996 to 2006, of the three big pharma firms publishing extensively, Merck published the most papers.

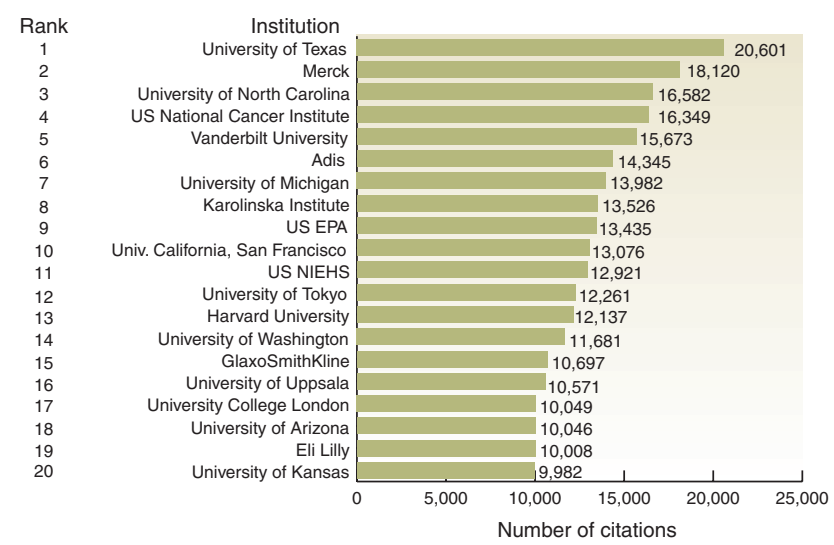

Source: In-Cites, Essential Science Indicators

Top cited paper by field

\begin{tabular}{|c|c|c|c|c|}
\hline Field & Author & Title & Citation & $\begin{array}{l}\text { Times } \\
\text { cited }\end{array}$ \\
\hline RNAi & Lim, L.P. et al. & $\begin{array}{l}\text { Microarray analysis shows that } \\
\text { some microRNAs downregulate } \\
\text { large numbers of target mRNAs }\end{array}$ & $\begin{array}{l}\text { Nature 433, } \\
769-773(2005)\end{array}$ & 313 \\
\hline Diagnostics & Lu, J. et al. & $\begin{array}{l}\text { MicroRNA expression profiles } \\
\text { classify human cancers }\end{array}$ & $\begin{array}{l}\text { Nature 435, } \\
834-838(2005)\end{array}$ & 252 \\
\hline Vaccinology & $\begin{array}{l}\text { Lindenbach, } \\
\text { B.D. et al. }\end{array}$ & $\begin{array}{l}\text { Complete replication of } \\
\text { hepatitis } C \text { virus in cell culture }\end{array}$ & $\begin{array}{l}\text { Science 309, } \\
623-626(2005)\end{array}$ & 209 \\
\hline $\begin{array}{l}\text { Embryonic stem } \\
\text { cells }\end{array}$ & $\begin{array}{l}\text { Boyer, L.A. } \\
\text { et al. }\end{array}$ & $\begin{array}{l}\text { Core transcriptional regulatory } \\
\text { circuitry in human embryonic } \\
\text { stem cells }\end{array}$ & $\begin{array}{l}\text { Cell 122, } \\
\text { 947-956 (2005) }\end{array}$ & 173 \\
\hline Assays & $\begin{array}{l}\text { Fabian, M.A. } \\
\text { et al. }\end{array}$ & $\begin{array}{l}\text { A small molecule-kinase } \\
\text { interaction map for clinical } \\
\text { kinase inhibitors }\end{array}$ & $\begin{array}{l}\text { Nature } \\
\text { Biotechnology } \\
23,329-336 \\
(2005)\end{array}$ & 153 \\
\hline Proteomics & $\begin{array}{l}\text { Anderson, N.L. } \\
\text { et al. }\end{array}$ & Nucleolar proteome dynamics & $\begin{array}{l}\text { Nature } 433 \\
77-83(2005)\end{array}$ & 145 \\
\hline Imaging & $\begin{array}{l}\text { Lidke, D.S. } \\
\text { et al. }\end{array}$ & $\begin{array}{l}\text { Sub-diffraction-limited optical } \\
\text { imaging with a silver superlens }\end{array}$ & $\begin{array}{l}\text { Science 308, } \\
534-537(2005)\end{array}$ & 141 \\
\hline $\begin{array}{l}\text { Computational } \\
\text { biology }\end{array}$ & $\begin{array}{l}\text { Tompa, M. } \\
\text { et al. }\end{array}$ & $\begin{array}{l}\text { Assessing computational tools } \\
\text { for the discovery of transcription } \\
\text { factor binding sites }\end{array}$ & $\begin{array}{l}\text { Nature } \\
\text { Biotechnology } \\
23,137-304 \\
(2005)\end{array}$ & 124 \\
\hline Gene therapy & $\begin{array}{l}\text { Tuszynski, } \\
\text { M.H. et al. }\end{array}$ & $\begin{array}{l}\text { A phase } 1 \text { clinical trial of nerve } \\
\text { growth factor gene therapy for } \\
\text { Alzheimer disease }\end{array}$ & $\begin{array}{l}\text { Nature Medicine } \\
11,551-555 \\
(2005)\end{array}$ & 83 \\
\hline Nanobiotech & $\begin{array}{l}\text { Patolsky, F. } \\
\text { et al. }\end{array}$ & $\begin{array}{l}\text { Immunotargeted nanoshells for } \\
\text { integrated cancer imaging and } \\
\text { therapy }\end{array}$ & $\begin{array}{l}\text { Nano Letters 5, } \\
\text { 709-711 (2005) }\end{array}$ & 81 \\
\hline $\begin{array}{l}\text { Environmental } \\
\text { biotech }\end{array}$ & $\begin{array}{l}\text { Goldman, E.R. } \\
\text { et al. }\end{array}$ & $\begin{array}{l}\text { A hybrid quantum dot-antibody } \\
\text { fragment fluorescence reso- } \\
\text { nance energy transfer-based } \\
\text { TNT sensor }\end{array}$ & $\begin{array}{l}\text { Journal of } \\
\text { the American } \\
\text { Chemical Society } \\
18,6744-6751 \\
(2005)\end{array}$ & 58 \\
\hline Plant biotech & Tohge, T. et al. & $\begin{array}{l}\text { Functional genomics by } \\
\text { integrated analysis of metabo- } \\
\text { lome and transcriptome of } \\
\text { Arabidopsis plants over-express- } \\
\text { ing an MYB transcription factor }\end{array}$ & $\begin{array}{l}\text { Plant Journal 2, } \\
218-235 \text { (2005) }\end{array}$ & 56 \\
\hline
\end{tabular}

Gaspar Taroncher-Oldenburg is Editor, Nature Special Pharma Projects and Andrew Marshall is Editor, Nature Biotechnology 